\title{
The Analysis of Multilevel Networks in Organizations: Models and Empirical Tests
}

Organizational Research Methods 2015, Vol. 18(3) 542-569 (C) The Author(s) 2015 Reprints and permission: sagepub.com/journalsPermissions.nav DOI: 10.1 | $77 / 1094428$ | I5579225 orm.sagepub.com

@SAGE

\author{
Paola Zappa' and Alessandro Lomi'
}

\begin{abstract}
Studies of social networks in organizations confront analytical challenges posed by the multilevel effects of hierarchical relations between organizational subunits on the presence or absence of informal network relations among organizational members. Conventional multilevel models may be usefully adopted to control for generic forms of non-independence between tie variables defined at multiple levels of analysis. Such models, however, are unable to identify the specific multilevel dependence mechanisms generating the observed network data. This is the basic difference between multilevel analysis of networks and the analysis of multilevel networks. The aim of this article is to show how recently derived multilevel exponential random graph models (MERGMs) may be specified and estimated to address the problems posed by the analysis of multilevel networks in organizations. We illustrate our methodological proposal using data on hierarchical subordination and informal communication relations between top managers in a multiunit industrial group. We discuss the implications of our results in the broader context of current theories of organizations as connected multilevel systems.
\end{abstract}

\section{Keywords}

multilevel exponential random graph models, multilevel models, multilevel networks, organizational networks, social networks, organizational design

\section{Introduction}

Research in organizational behavior (OB) has long been aware of the need to develop a multilevel understanding of individual behavior in organizations (Porter \& Schneider, 2014). Somewhat more recently, a similar awareness also spilled over to neighboring research fields such as organizational psychology (Zohar \& Luria, 2005), human resource management (HRM) (Wright \& Boswell, 2002), organization and management theory (OMT) (Ibarra, Kilduff, \& Tsai, 2005; Lomi \& Larsen, 2001), and management information systems (MIS) (McLaren, Head, Yuan, \& Chan, 2011). Multilevel

\footnotetext{
'Social Network Analysis Research (SoNAR) Center, University of Italian Switzerland, Lugano, Switzerland

Corresponding Author:

Paola Zappa, Social Network Analysis Research (SoNAR) Center, University of Italian Switzerland, Via G. Buffi, 13 - 6904 Lugano, Switzerland.

Email: paola.zappa@usi.ch
} 
models are now common also in studies of leadership (Yammarino, Dionne, Chun, \& Dansereau, 2005) and in research on human and social capital (Oh, Labianca, \& Chung, 2006; Ployhart \& Moliterno, 2011). One consequence of these developments has been the progressive diffusion of multilevel research methods for studying organizations (Bliese, Chan, \& Ployhart, 2007; Klein \& Kozlowski, 2000; Scherbaum \& Ferreter, 2009).

Despite this extensive organizational literature, developing models capable of capturing multilevel mechanisms has proved particularly elusive for researchers interested in social networks (Brass, Galaskiewicz, Greve, \& Tsai, 2004). This state of affairs is surprising given the considerable body of organizational research contributed by social network perspectives (Borgatti \& Foster, 2003; Brass, Labianca, Mehra, Halgin, \& Borgatti, 2014; Moliterno \& Mahony, 2011). As Contractor, Wasserman, and Faust observe (2006):

One of the key advantages of a network perspective is the ability to collect, collate, and study data at various levels of analysis .... However, for the purposes of analyses most network data are either transformed to a single level of analysis ... which necessarily loses some of the richness in the data, or are analyzed separately at different levels of analysis thus precluding direct comparisons of theoretical influences at different levels. (p. 684)

In an attempt to address this analytical concern, models for the analysis of multilevel networks have been recently proposed within the more general analytical framework of exponential random graph models (ERGMs), a family of stochastic models for the analysis of social networks (Snijders, Pattison, Robins, \& Handcock, 2006). Exponential random graph models allow examining networks at a single level of analysis. Multilevel exponential random graph models (MERGMs) add the possibility of testing hypotheses about how the presence of ties (i.e., social relations) among lower-level actors or units (e.g., among individuals) depend on the presence of ties among higher-level actors or units (e.g., among organizational subunits) (Wang, Robins, Pattison, \& Lazega, 2013). This analytical framework would be clearly valuable in studying organizations where connected individuals are typically contained in more aggregate structures (subunits), which may themselves be connected through, for example, workflow or hierarchical relations. While alternative statistical models exist for studying organizational social networks, MERGMs are the only existing models that allow direct modeling of interdependences induced by known relational mechanisms. Common examples of such mechanisms include reciprocity (the tendency of individuals to prefer social relations characterized by mutuality) and transitivity (the tendency of individuals sharing partners to become directly connected).

MERGMs have not been developed specifically for studying networks within organizations. While ERGMs are becoming more common in organizational research (Lomi, Lusher, Pattison, \& Robins, 2013), no empirical application is yet available where MERGMs are adopted for the analysis of social networks across multiple organizational levels. To the best of our knowledge, this article provides the first application of MERGMs to the analysis of intraorganizational relations.

Unlike more general multilevel models used in organizational research, MERGMs are crosssectional models derived specifically for tie variables: MERGMs are designed to test hypotheses about mechanisms underlying the presence of relations between individuals in organizations. MERGMs do not assume that interdependence between organizational members derives only from common membership in organizational subunits. More specifically, MERGMs recognize that organizational subunits such as, for example, divisions, subsidiaries, or project teams, have an internal structure and that members occupy differentiated positions in this structure. MERGMs also recognize that organizational subunits themselves may be connected, thus introducing important elements of realism in studies of organizational networks. Organizations are more than anything else hierarchical social systems with multiple and partially nested levels of action (March \& Simon, 1958; Simon, 
1996). Perhaps the most obvious implication of adopting organizations as settings for studying social networks is that hierarchical elements shape the interaction among organizational members within but also across structural layers. For this reason, it is important to have available specialized models that may be specified to assess the influence that the structure of relations at one level exerts on the structure of relations at another level (Moliterno \& Mahony, 2011).

In this article, we introduce MERGMs and illustrate how they may be useful to understand interpersonal networks of communication relations among the members of a top management team in a multiunit industrial group. In the empirical case study we present, subsidiary companies are the higher-level actors. Members of the top management team are the lower-level actors. We are interested in understanding the extent to which interpersonal communication relations crosscutting the boundaries of the subsidiaries (lower-level ties) are affected by hierarchical relations existing between the subsidiaries (higher-level ties). We clarify the difference between multilevel analysis of social networks and multilevel network analysis by providing a detailed guide to specification and empirical estimation of MERGMs.

Our more specific objective is to clarify the social and organizational mechanisms affecting the likelihood that informal communication networks will cross-cut the formal organizational boundaries encircling the subsidiary units. This objective is analytically important because research on social networks conducted at a single level is incapable of establishing the autonomy of informal boundary spanning interaction with respect to formal relations existing between organizational subunits containing the individuals. This objective is also substantively important given the farreaching implications of boundary crossing interaction for a variety of organizational outcomes (Burt, 2004; Hansen, 1999; Reagans \& McEvily, 2003).

The article is organized as follows. In the next section, we outline the motivation for developing models for multilevel networks. In the third section, we introduce the MERGM class of models, define their main analytical components, and state their main underlying assumptions. In the fourth section, we describe the research design behind our empirical illustration. We briefly discuss the variables, the measures needed for the specification of the empirical model, and the computational approach for estimating and evaluating MERGMs. In the fifth section we report the empirical estimates and provide an overall diagnostic evaluation of the model. We conclude with a short discussion on the general usefulness, applicability, and limitations of MERGMs in organizational research.

\section{General Background and Motivation}

\section{Multilevel Models in Organizations}

Organizations are a prototypical example of hierarchical multilevel social system (Kozlowski \& Klein, 2000). Until relatively recent times, however, this observation has not been accompanied by a parallel development of analytical approaches to the study of organizational behavior across multiple levels (Porter \& Schneider, 2014). Thanks to advances in multilevel analysis, the situation is now rapidly changing within organization studies in general-and more specifically within the fields of organizational behavior, including leadership (Beal \& Dawson, 2007; Bliese, Halverson, \& Schriesheim, 2002; Hirst, Van Knippenberg, Chen, \& Sacramento, 2011), human resource management (Bell, Towler, \& Fisher, 2011), organizational communication (Monge \& Contractor, 2003), and organization and management theory (Contractor et al., 2006).

In the typical organization, members are affiliated to internal subunits or work teams. Internal subunits and teams are part of companies. Companies (subsidiaries) in turn may be contained in larger multiunit corporate formations (Granovetter, 2005; Hofmann, 1997). Group factors produced by common membership in superordinate subunits are important sources of nonindependence in individual behavior. Because of the well-known statistical problems ${ }^{1}$ caused by lack of 
independence in behavioral data, an increasing number of papers relies on multilevel modeling techniques to assess the influence of group factors on lower-level outcomes - typically on organizational members' attitudes and behaviors.

Multilevel models specify a set of lower- and higher-level actor covariates that are expected to explain lower-level outcome variables. In order to capture the total variance of the outcome variable(s), multilevel models estimate regression coefficients of lower-level variables and model between-groups variation in an attempt to partial out the effect of the higher-level term (Hofmann, 1997). Various specifications have been introduced to deal with different data structures and research purposes (for a review, see Bryk \& Raudenbush, 1992). A number of methods have been proposed to alleviate issues of endogeneity - a central problem in assessing causality (Antonakis, Bendahan, Jacquart, \& Lalive, 2010).

Multilevel modeling techniques have been successfully applied to a considerable variety of organizational phenomena. In studies of leadership, for example, multilevel models have been adopted to assess the effect of common group factors (e.g., complexity, professionalism and culture) on leadership emergence and performance (Mumford, Antes, Caughron, \& Friedrich, 2008). In the study of organizational socialization, team expectations and team performance have been shown to differently predict initial performance and performance improvement of newcomers (Chen, 2005). Despite these and related examples of successful organizational applications of multilevel models, the core insights of multilevel analysis does not extend directly to the analysis of multilevel networks. This is the main motivation for recent attempts to develop the specialized models for the analysis of multilevel networks that we discuss in this article.

\section{Networks in Organizations}

Over the past two decades or so, organizational and management research has emphasized the multiple roles that social networks play in organizations (Borgatti \& Forster, 2003; Brass et al., 2004; Carpenter, Li, \& Jiang, 2012). For example, research in organizational behavior instructs us that organizational members with high self-monitoring tendencies are more likely to occupy central positions in organizational networks (Mehra, Kilduff, \& Brass, 2001) and that innovative ideas are more likely to originate with individuals occupying boundary spanning roles — or network positions connecting disjoint third parties (Burt, 2004).

More generally, the presence and absence of relations between organizational members has been shown to be systematically associated to important interpersonal differences in productivity (Reagans \& Zuckerman, 2001), resources (Podolny \& Baron, 1997), reputation (Kilduff \& Krackhardt, 1994), propensity to innovate (Hansen, 1999), power (Brass \& Burkhardt, 1993), and autonomy (Burt, 1992).

Networks exist at different organizational levels. Within-organization networks may be observed between individuals, subunits, teams, departments, or subsidiaries (Borgatti \& Forster, 2003). Most available studies have analyzed these networks separately, typically ignoring the possible existence of dependencies across levels-multilevel network dependencies.

Because lower-level actors are nested in higher-level actors (groups in standard multilevel modeling), relations between lower-level actors are nested in higher-level relations. Not surprisingly, awareness is increasing of the need to devote attention to antecedents and consequences of multilevel networks of this kind (Baum \& Ingram, 2002; Brass, 2000; Brass et al., 2004; Oh et al., 2006).

Analyzing multilevel network systems involves specifying "how an observed network structure at one level of the system of organizational networks relates to network structures and effects at higher or lower levels of the system" (Moliterno \& Mahony, 2011, p. 443). Building on this view, models for multilevel networks specify how relations between individuals in organizations are 
shaped by (1) their joint membership in more aggregate units and (2) the presence of relations between such units. Multilevel network models of this kind would have wide applicability.

Studies of leadership, for example, frequently apply a relational framework to identify emergent leaders, defined as organizational members recognized and nominated as leaders by their network peers (Balkundi \& Kilduff, 2006). Similarly, studies of organizational reputation demonstrate that perceived network connections to prominent friends increase the reputation of individuals for high performance (Kilduff \& Krackhardt, 1994). Despite the apparent validity of these results, a detailed analysis of the organizational setting would be needed to rule out the possibility that individual outcomes (e.g., leadership or reputation) are a consequence of membership in subunits occupying a specific position in the network of formal hierarchical reporting relations or in the workflow network. Without such assessment, it may be misleading to associate measures of leadership or reputation exclusively to personal characteristics or positions that individuals occupy in informal social networks within their subunits (Carson, Tesluk, \& Marrone, 2007).

In summary, the multilevel character of interpersonal networks within organizations makes it necessary to develop a multilevel understanding of social networks, particularly-although not exclusively-when they are observed in intraorganizational contexts. Such understanding requires specification of specialized models for multilevel networks of the kind we illustrate in the empirical part of the article. Before we do so, however, we need to clarify the fundamental differences between multilevel models for networks and models for multilevel networks. The first class of models has found wide application in the study of organizational behavior (Rousseau, 1985) and consists of standard hierarchical linear models (HLMs), which specify relational characteristics of individuals - affiliated to different subunits - within their own network and, possibly, characteristics of individuals and subunits as predictors of individual behavior ( $\mathrm{Li}, 2013)$. The second class of models is more recent and significantly less developed. We discuss these models next.

\section{Models for Multilevel Networks in Organizations}

The models for multilevel networks differ from standard multilevel models in at least two respects. First, multilevel network models take relations, rather than actors, as the focal element of analysis (Brass, 2000) — namely, as the outcome variable. Network models are models for tie variables. Their main objective is to explain the presence or absence of ties between lower-level actors contained in more aggregate units - namely, higher-level actors - that may themselves be connected. As such, network models are not general purpose models. They are useful only insofar as one pursues specific analytical objectives requiring estimation of the probability of observing a tie between two actors.

Second, multilevel network models are defined by hypothesis about interdependence among tie variables specified at different levels of analysis. The predictors of the outcome tie variable are local configurations of network ties. Local configurations represent relational mechanisms-like reciprocity and transitivity, mentioned previously - and are defined across multiple levels (Wang, Robins, Pattison, \& Lazega, 2013). The objective of multilevel network models is to assess the effect of higher-level predictors on the probability of observing a network tie rather than estimating between group variations (Bryk \& Raudenbush, 1992).

Because of these differences, standard multilevel statistical models (HLMs) apply only imperfectly to multilevel network problems. Available multilevel models can be adapted to social networks because they can control for the effect of (lower- and higher-level) relational predictors like centrality measures on lower-level behaviors. This approach can successfully deal with endogeneity and other vexing statistical issues, as $\mathrm{Li}$ (2013) shows in a comprehensive review on regression methods applied to network data. However, conventional multilevel models typically adopted in the study of organizations would be of limited assistance in examining network interdependences 
Table I. Comparison Between Models for Multilevel Analysis, Multilevel Analysis of Networks, and Multilevel Network Analysis.

\begin{tabular}{|c|c|c|c|}
\hline & Multilevel Analysis & $\begin{array}{l}\text { Multilevel Analysis } \\
\text { of Networks }\end{array}$ & Multilevel Network Analysis \\
\hline Object & $\begin{array}{l}\text { Assessing the dependence } \\
\text { of a lower-level actors' } \\
\text { behavior on lower- and } \\
\text { higher-level actors' } \\
\text { individual characteristics }\end{array}$ & $\begin{array}{l}\text { Assessing the dependence of } \\
\text { a lower-level actors' } \\
\text { behavior on lower-level } \\
\text { actors' individual and } \\
\text { RELATIONAL } \\
\text { characteristics and on } \\
\text { higher-level actors' } \\
\text { individual characteristics }\end{array}$ & $\begin{array}{l}\text { Assessing the } \\
\text { interdependence between } \\
\text { RELATIONAL } \\
\text { characteristics of lower- } \\
\text { and higher-level actors }\end{array}$ \\
\hline Model & HLMs & $\begin{array}{l}\text { HLMs with network } \\
\text { measures of lower-level } \\
\text { actors' position as } \\
\text { predictors }\end{array}$ & MERGMs \\
\hline Data structure & $\begin{array}{l}\text { A vector for a lower-level } \\
\text { actors' outcome variable } \\
\text { and a set of vectors for } \\
\text { lower- and higher-level } \\
\text { actors' variables } \\
\text { A vector for a variable } \\
\text { representing affiliation of } \\
\text { lower- to higher-level } \\
\text { actors }\end{array}$ & $\begin{array}{l}\text { A vector for a lower-level } \\
\text { actors' outcome variable } \\
\text { and a set of vectors for } \\
\text { lower- and higher-level } \\
\text { actors' variables } \\
\text { A binary square matrix } \\
\text { representing a lower-level } \\
\text { network (then converted } \\
\text { into a set of vectors for } \\
\text { relational variables) } \\
\text { A vector for a variable } \\
\text { representing affiliation of } \\
\text { lower- to higher-level } \\
\text { actors }\end{array}$ & $\begin{array}{l}\text { A set of vectors for lower- } \\
\text { and higher-level actors' } \\
\text { variables } \\
\text { A binary square matrix } \\
\text { representing a higher- } \\
\text { level network and a binary } \\
\text { square matrix } \\
\text { representing a lower- } \\
\text { level network } \\
\text { A rectangular matrix } \\
\text { representing affiliation of } \\
\text { lower- to higher-level } \\
\text { actors }\end{array}$ \\
\hline Possible extensions & Treatment of panel data & Treatment of panel data & Cross-sectional data only \\
\hline
\end{tabular}

Note: In multilevel analysis and multilevel analysis of networks models can be specified so that they include either fixed or random effects. HLMs = hierarchical linear models; MERGMs = multilevel exponential random graph models.

across levels as such models do not allow specification and identification of the form that such interdependences might take (see Table 1).

With respect to multilevel issues, as Lazega, Jourda, Mounier, and Stofer (2008) put it: "Although the multilevel dimension is intrinsic to the analysis of social networks, the analysis of relationship between structures of different levels remains underdeveloped" (p. 160). Most of the empirical studies available have relied on various forms of simplification of the data structure in order to account for multilevel effects.

The typical approach consists in reducing a multilevel network to a single-level network, with a set of actors (individuals or subunits) and two relations among them, to analyze the resulting network with standard social network analysis methods. Fernandez (1991), for example, in a study on emergent leadership, represents the formal hierarchical structure among divisions of a multiunit organization - which is an inherently interunit relation (Hansen, 1999) — in a fine-grained way, as the "reporting to" relation among organizational members affiliated to the various divisions. He analyzes this relation together with informal relation of "respect" and "friendship." By contrast, Tsai (2002), in examining cooperation and competition within a multiunit organization, represents informal knowledge sharing as a relation between subunits and examines it together with formal cooperation ties. By assuming that relations are isomorphic across levels (Rousseau, 1985), this 
approach disregards the multilevel nature of the data structure. In doing so, this approach is likely to alter the relationships in the data and to increase the risk of misspecification or other statistical issues well documented in multilevel modeling (Hofmann, 1997; Rousseau, 1985).

\section{Multilevel Exponential Random Graph Models}

\section{The Structure of Multilevel Networks}

ERGMs are becoming increasingly common in studies of inter- and intra-organizational relations (Lusher, Koskinen, \& Robins, 2013). The ERGM framework allows investigating the development of networks and, mainly, structural "patterns and precursors of network formation" (Carpenter et al., 2012, p. 1340). For instance, Srivastava and Banaji (2011) apply ERGMs to assess the association between self-related cognition and tendency to collaborate in a biotechnology company.

MERGMs (Wang, Robins, Pattison, \& Lazega, 2013) are a new class of ERGMs specifically designed for the analysis of multilevel social networks. They are currently the only available method for the analysis of multilevel networks.

ERGMs - and MERGMs - have a common origin in logistic regression but differ markedly from standard logistic regression techniques typically used to model network ties. While standard regression models require independence of observations, ERGMs are designed for network data, whose observations (i.e., the ties) are linked by complex interdependencies (Pattison \& Robins, 2002). ERGMs provide a more direct methodological solution to the lack of independence problem that is unavoidable in network data (Snijders et al., 2006). The purpose of ERGMs is not to control endogenous interdependence between tie variables but, rather, to model directly the underlying mechanisms responsible for observed interdependencies among network ties.

\section{Multilevel Network Data}

MERGMs have been derived for cross-sectional analysis of tie variables. They are less useful if one is interested in modeling nonrelational behavioral variables or in identifying how different levels account for variance in individual behavior. In their current version, MERGMs may be specified only for two-level networks. Like ERGMs from which they are derived, MERGMs are models for complete (rather than ego-centered) networks (Lusher et al., 2013). The central question that MERGMs may help to address is: How are relations between lower-level actors (e.g., organizational members) affected by the presence of connections between higher-level actors (e.g., organizational subunits) containing them? To the extent that relations between organizational subunits are mandated (or "formal") and relations between organizational members are emergent (or "informal"), MERGMs may be adopted to address questions about the extent to which latter kind of relations in organizations are actually independent from the former. According to McEvily, Soda, and Tortoriello (2014), this is an important question that is rarely asked in empirical studies of social networks in organizations. This is the case, in part, because appropriate analytical approaches have been unavailable until very recently.

The setting that is typically appropriate for an analysis of multilevel networks involves a multiunit organization whose members are affiliated to at least one subunit-where subunits may be divisions, functions, work teams, projects, or subsidiaries. Organizations are of different size. In published papers based on ERGMs, the number of network actors ranges from very small-around 30 (Snijders et al., 2006) - to fairly large-around 1,700 (Goodreau, 2007).

Network relations of interest are defined among organizational members and among organizational subunits and may have several contents. In the example that we present in the following section of the paper, organizational members are managers of a multiunit organization, 


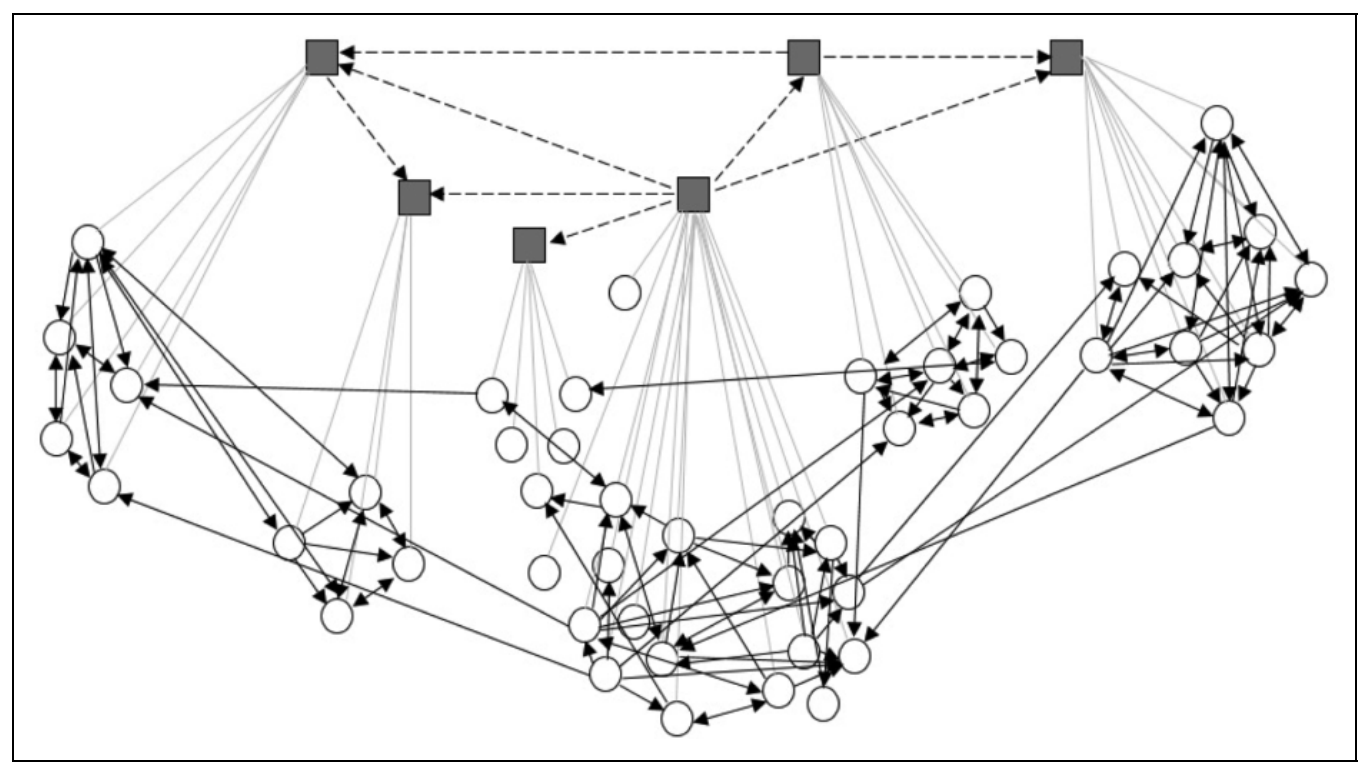

Figure I. Multilevel empirical network. Squares denote organizational subunits - subsidiary companies (U) in our data -. Circles denote individuals - managers $(P)$ in our data -. Dashed black ties are relations of hierarchical subordination between pairs of subunits (A). Solid black ties are informal communication relations between pairs of individuals (B). Grey ties are affiliation relations of individuals to subunits (X).

organizational subunits are the subsidiary units of the organization, network ties among members are an informal communication relation on work-related matters, while network ties among subunits are a hierarchical subordination relation. Examples of relations among organizational members include also advice seeking/giving, trust, and knowledge searching, transferring, and sharing. Examples of relations among organizational subunits include workflow, reporting, and various types of resource dependencies.

Multilevel network analysis starts with the identification of a set of lower-level actors $\boldsymbol{P}$ (e.g., organizational members), an affiliation set $\boldsymbol{U}$ (e.g., organizational subunits), and observations of network ties $(\boldsymbol{R})$ within and between elements of these sets. Suppose that $\boldsymbol{P}$ is the set of organizational members and that $\boldsymbol{B}$ is a binary social relation defined between them (where $\boldsymbol{B}$ stands for relations defined between lower-level actors). Suppose, further, that $\boldsymbol{U}$ is a set of organizational subunits and that $\boldsymbol{A}$ is a binary relation defined between them (where $\boldsymbol{A}$ stands for relations defined between higher-level actors). Finally, suppose that $\boldsymbol{X}(=\boldsymbol{P} \times \boldsymbol{U})$ is a bipartite binary association between elements of $\boldsymbol{P}$ and elements of $\boldsymbol{U}$ (where $\boldsymbol{X}$ stands for relations defined between actors across different levels). Then a multilevel network is simply a tuple $\boldsymbol{M}=[\boldsymbol{P}, \boldsymbol{U}, \boldsymbol{B}, \boldsymbol{A}, \boldsymbol{X}]$. To fix ideas, in the case study we develop in the empirical part of the study $\boldsymbol{P}$ is the set of top managers in a multiunit group and $\boldsymbol{B}$ is the network of informal communication observed between them. $\boldsymbol{U}$ is the set of subsidiary companies to which the different managers are affiliated, and $\boldsymbol{A}$ is a relation of hierarchical subordination defined between the subsidiaries. Finally, $\boldsymbol{X}$ is a binary cross-level relation affiliating managers to subsidiary companies.

In the empirical example we develop next, we also collected data on attributes that may affect the likelihood of observing network relations within and across network levels.

Figure 1 reports a network diagram of the data we analyze in the empirical part of the article. Squares are subsidiary companies $(\boldsymbol{U})$. Circles are managers $(\boldsymbol{P})$. Dashed black ties are 
relations of hierarchical subordination between pairs of subsidiary companies $(\boldsymbol{A})$. Solid black ties are informal communication relations between pairs of managers $(\boldsymbol{B})$. An arrow signals the direction of the network tie. Grey links are affiliation ties of managers to subsidiaries $(\boldsymbol{X})$.

\section{Model Definition and Notation}

Assume that $\boldsymbol{M}$ is a multilevel network consisting of $i=1, \ldots j, \ldots, v$ lower-level actors $(\boldsymbol{P})$ and $l=1, \ldots k, \ldots, u$ higher-level actors $(\boldsymbol{U}) . M_{i j}$ - the generic network tie between $i$ and $j$-is conceived as a random variable with observed value $m_{i j}$. $M_{i j}=1$ if there is a tie from $i$ to $j$ and $M_{i j}=0$ otherwise.

MERGMs model the probability that a tie from $i$ to $j$ exists (so, a binary response variable) as a linear function - in logit form - of predictors. Each predictor corresponds to a network configuration - namely, a small subset of ties involving $i$, and capturing a relational mechanism (or social process, as a synonym) going on around $i$ and assumed to generate the predicted tie $m_{i j}$.

The MERGM formulation looks similar to binary logistic regression, with the main difference that the same tie is present on both sides of the equation and in multiple predictors. ${ }^{2}$ Each configuration may be associated with a parameter that can be estimated from data. This is a crucial difference between MERGMs and HLMs with random (varying across higher-level actors) or fixed (constant across higher-level actors) effects. HLMs can control for generic forms of dependence but cannot model them directly (Hofmann, 1997). For example, HLMs can control for the lack of dependence induced by social mechanisms, such as - for example - reciprocity or transitivity. HLMs, however, cannot model these mechanisms directly.

MERGMs may be specified as:

$$
\operatorname{Pr}(M=m \mid Y=y)=\frac{1}{\kappa(\theta)} \exp \sum_{Q}\left\{a_{Q} z_{Q}^{T}(m)+\theta_{Q^{2}} z_{Q}^{T}(m, y)\right\}
$$

where:

- $\quad \boldsymbol{M}$ is the set of all possible multilevel networks of size $(v \times u)$ and $\boldsymbol{m}$ is the observed network. $\boldsymbol{M}$ can be thought of as the matrix of all the random variables $M_{i j}$, with observed value $\boldsymbol{m}$.

- $\boldsymbol{Y}$ is a set of vectors of individual- and subunit-specific characteristics and $y$ is the observed set.

- $Q$ indicates the potential network configurations - as discussed in the next section (Robins, Elliott, \& Pattison, 2001). The summation $\Sigma$ is over all different configurations included in the model.

- $z_{Q}(m)=\sum_{m} \prod_{M_{i j \in Q}} m_{i j}$ are structural and $z_{Q}(m, y)=\sum_{m} \prod_{M_{i j \in Q}} m_{i j} y_{i}$ are covariate network statistics corresponding to configuration $Q$. The statistics count, for each actor in the network, the number of configurations of each type in which the actor is involved - for example, the number of reciprocal ties including actor $i$.

- $a_{Q}$ are structural and $\theta_{Q}$ covariate parameters corresponding to configuration $Q$. The parameters can be interpreted as "conditional" log-odds of logistic regression and converted into odds and binary probabilities. A large and positive (negative) parameter estimate implies that the network contains more (less) configurations of that kind than those expected by chance. According to the tie interdependence assumption, a possible tie between two actors $i$ and $j$ is assumed to be contingent-formally, "conditionally dependent"- on any other tie involving $i$ or $j$. The same assumption applies, therefore, to the statistics involving $i$ and $j$. Also each parameter cannot be interpreted as an independent 
predictor but is conceived as "conditional on (the presence and value of) the others" (Robins, Snijders, Wang, Handcock, \& Pattison, 2007).

- $\kappa(\theta)_{Q}$ is a normalizing constant included to ensure that the sum of probabilities in (1) over all possible $\boldsymbol{m}$ equals 1 .

Equation 1 describes a general probability distribution of networks. It assumes that the probability of observing the empirical multilevel network structure depends on a small set of configurations, typically included according to theoretical assumptions on actor relational behavior in the context under examination (Wang, Robins, Pattison, \& Lazega, 2013).

\section{Network Configurations Within and Across Levels}

Structural configurations are a distinctive feature of ERGMs and consist of a small subset of ties (Snijders et al., 2006). The analytical objective of ERGMs is to estimate the incidence of these configurations on the probability of observing network ties between two actors. These configurations represent the interdependences between ties that standard statistical models usually ignore by either treating them as part of the error term (and then correcting generically the standard errors) or including them as individual attributes - such as, for example, centrality, reciprocity, or brokerage measures ( $\mathrm{Li}, 2013)$. None of these common model building strategies can capture the underlying mechanisms of tie formation that ERGMs explicitly specify.

The vector of structural statistics $z_{Q}(m)$ may include three level-specific configurations:

1a. Lower-level configurations investigate relations within the lower-level network $\boldsymbol{B}$, namely, $z_{Q}(b)$, accounting for various characteristics of the interaction between individuals (Snijders et al., 2006). Published organization research based on ERGMs typically includes the specification of these configurations only (Srivastava $\&$ Banaji, 2011). The configurations used in the empirical exercise are reported later in the paper in Table 4.

The higher-level configurations are the core part of MERGMs (Wang, Robins, Pattison, \& Lazega, 2013). These configurations model relations between hierarchical levels and are:

2a. Configurations accounting for the group effect-namely, the tendency of organizational members assigned to the same subunit(s) to interact with one another. Formally, these statistics link the network $\boldsymbol{X}$ to the lower-level network $\boldsymbol{B}$-namely, $z_{Q}(b, x)$.

3a. Configurations "express[ing] tendencies for structural [configurations] to be associated across both levels simultaneously" (Wang, Robins, Pattison, \& Lazega, 2013, p. 99). These configurations involve all the three networks - namely, $z_{Q}(a, x, b)$ - and are labeled as "cross-level" because include both lower-level and higher-level ties. These configurations allow probabilistic assessment of whether the position of organizational members in the interpersonal network or the ties between organizational members may be linked to the position of their subunits in the interunit network or to the ties between subunits.

The higher-level configurations used in the empirical exercise are reported later in the paper in Table 5.

Covariate configurations include actor characteristics (Robins et al., 2001; Wang, Robins, Pattison, Lazega, \& Jourda, 2013), specified as attributes of each actor or similarities between pairs of connected actors. Similarly to the vector of structural configurations, the vector of covariate configurations $z_{Q}(m, y)$ includes:

1b. Configurations accounting for the influence of organizational member $\left(y^{B}\right)$ attributes on interaction in network $\boldsymbol{B}-$ namely, $z_{Q}\left(b, y^{B}\right)$. These configurations may be specified to test 
whether organizational members are more likely to interact with others if they have some attributes or are similar to others in some attributes.

2b. Configurations accounting for the interdependence between lower-level and affiliation networks - namely, $z_{Q}\left(b, x, y^{B}\right)$. These configurations may be specified to test whether organizational members assigned to the same subunit are more likely to interact with one another if they have or are similar in some attributes.

3b. Configurations accounting for the influence of subunit attributes or organizational member attributes on the interdependence between lower- and higher-level ties-namely, $z_{Q}(a, b, x$, $\left.y^{A}, y^{B}\right)$. These configurations may be specified to test whether the association between interpersonal and interunit ties mentioned previously are more likely when organizational members or subunits have some attributes or are similar, respectively, to other organizational members/subunits in some attributes.

The lower- and higher-level covariate configurations used in the empirical exercise are reported later in the paper in Table 6.

\section{Empirical Illustration}

In the next section, we situate the model just discussed in the context of an analysis of knowledge sharing in a multiunit industrial company with five organizational subunits (subsidiary units or subsidiaries from now on). This organizational setting provides ideal testing grounds for the analysis of multilevel networks because: (a) Subsidiaries are designed to be repositories of specialized knowledge, (b) individuals across subsidiaries establish informal networks of communication relations to mobilize knowledge resources across organizational boundaries and have access to diversified knowledge, and (c) subsidiaries are connected by hierarchical reporting relations, which represent the formal organizational structure (Argote, McEvily, \& Reagans, 2003; Tushman, 1977).

The main goal of the analysis is to assess how the formal organizational structure sustains (or constrains) information sharing across organizational boundaries. More specifically we ask: How autonomous are boundary spanning ties? In other words, does informal interpersonal interaction span subsidiary boundaries independent of the formal hierarchy of relations existing between subsidiaries? Does the position (and therefore the role) of a subsidiary within the formal organizational structure make its members particularly active or attractive in informal interaction and thus contribute to explain individuals' position (and role) in information sharing? Finally, how do patterns of hierarchical relations linking the subsidiaries affect interpersonal interaction? These questions are at the heart of current research investigating the coupling/decoupling of formal and informal relations (Kleinbaum, Stuart, \& Tushman, 2013; McEvily et al., 2014) and trying to link properties of social networks to relevant organizational outcomes like innovation and performance (Burt, 2004; Dokko, Kane, \& Tortoriello, 2014; Tsai, 2001). As we demonstrate in the empirical example that we present next, these questions can be answered convincingly only by assuming-and testing - specific forms of multilevel network relations linking individuals, organizational subunits, and individuals and organizational subunits.

\section{Research Design}

\section{Data}

We studied an international multiunit industrial group active in the design, manufacturing, and sale of leisure motor yachts. The group consists of subsidiary units, and each organizational member is unambiguously and uniquely assigned to one subsidiary. Since the subsidiaries act as quasiindependent companies and occupy different market positions, coordination and collaboration 
Table 2. Basic Network Descriptive Statistics for the Interpersonal Network.

\begin{tabular}{lc}
\hline Statistics & Values \\
\hline Density & 0.08 \\
Number of ties & 164 \\
Mean in-/out-degree & 3.49 \\
Standard deviation in-/out-degree & $1.85-2.65$ \\
Minimum in-/out-degree & 0 \\
Maximum in-/out-degree & $6-10$ \\
Number of reciprocated pairs & 55
\end{tabular}

across the boundaries of subsidiaries are crucial, especially for members working in the same functional areas. Boundary-spanning interaction would allow members in different subsidiary units to share information on technical solutions, potential customers, or competitors.

We examined informal relations of interpersonal communication among the 47 members of the group top-management team $(\boldsymbol{P}) .^{3}$ Each participant was administered a questionnaire, containing the list of names of the other 46 managers, and was asked to report the presence of personal communication ties (McCulloh, Armstrong, \& Johnson, 2013). The question was framed in terms of advice - at least on a daily frequency - on work-related matters (e.g., information about dealers, competitors, production delays). We obtained a $100 \%$ response rate. We arranged the data in matrix $\boldsymbol{B}(47 \times 47)$ : the generic cell $b_{i j}=1$ if manager $i$ communicates with manager $j$ on work-related matters on a daily basis at least.

Hierarchical relations between subsidiaries $(\boldsymbol{U})$ were reconstructed by asking the corporate CEO to indicate "who reports to whom." We provided him with the names of the 47 participants arranged in the rows and in the columns of a square matrix. We asked him to indicate whenever the column person reported to the row person. For example, if the "Chief engineer" (column) $j$ in subsidiary $k$ reported to the "Chief Corporate Engineer" (row) $i$ in subsidiary $l$, then $a_{i j}=1$. In this case, $i$ would be hierarchically superordinate to $j(i \rightarrow j)$. We arranged these data into the matrix between the subsidiaries, ${ }^{4} \boldsymbol{A}(6 \times 6)$ : the generic cell $a_{l k}=1$ if subsidiary $l$ is hierarchically superordinate to subsidiary $k$, namely, if there is at least one manager $j$ in $k$ reporting to a manager $i$ in $l$.

We linked managers to subsidiaries in the (managers by subsidiary) matrix of containment relations $X(47 \times 6)$ : the generic cell $x_{i l}=1$ if manager $i$ belongs to subsidiary $l$.

Finally, we used $\boldsymbol{B}, \boldsymbol{A}$, and $\boldsymbol{X}$ to build $\boldsymbol{M}=[\boldsymbol{P}, \boldsymbol{U}, \boldsymbol{A}, \boldsymbol{B}, \boldsymbol{X}]$.

A different section of the questionnaire was designed to elicit demographic and organizational information that was used to construct the control variables included in our empirical model specifications. Table 2 and Table 3 report the basic descriptive statistics computed, respectively, for the interpersonal network and for the control variables.

\section{Empirical Model Specification}

To model interpersonal interaction, we specify a set of configurations that, according to theory, are likely to shape a communication network (class 1a displayed in Table 4).

Density accounts for the general propensity of managers toward communicating with others. Because building and maintaining many relations is costly, this tendency is usually negative. Reciprocity tests the likelihood that two managers reciprocate relations, exchanging information with one another. Popularity spread examines the likelihood that few managers are particularly popular-namely, are chosen as communication partners and receive diversified information from many 
Table 3. Basic Descriptive Statistics for Individual and Subunit Covariates.

\begin{tabular}{|c|c|c|}
\hline & Relative Frequency (\%) & Mean $(S D)$ \\
\hline \multicolumn{3}{|l|}{ Individual attributes } \\
\hline \multicolumn{3}{|l|}{ Function (i.e., membership in organizational function) } \\
\hline CEO & 12.8 & \\
\hline Engineering & 12.8 & \\
\hline Finance & 14.9 & \\
\hline Marketing & 8.5 & \\
\hline Production & 25.5 & \\
\hline Others & 25.5 & \\
\hline \multicolumn{3}{|l|}{ Gender } \\
\hline Female & 14.9 & \\
\hline Male & 85.1 & \\
\hline \multicolumn{3}{|l|}{ Grade (i.e., level of task performed) } \\
\hline Clerk & 12.8 & \\
\hline Operations manager & 34.0 & \\
\hline Manager & 42.6 & \\
\hline Consultant & 10.6 & \\
\hline \multicolumn{3}{|l|}{ Nationality } \\
\hline Italian & 87.2 & \\
\hline Others & 12.8 & \\
\hline $\begin{array}{l}\text { Tenure (i.e., number of years since an organizational member joined } \\
\text { the group) }\end{array}$ & & $8.1(7.5)$ \\
\hline \multicolumn{3}{|l|}{ Subunit attributes } \\
\hline \multicolumn{3}{|l|}{ Country (i.e., country where a subunit is based) } \\
\hline Italy & 66.6 & \\
\hline US & 16.7 & \\
\hline International (i.e., no country based) & 16.7 & \\
\hline \multicolumn{3}{|l|}{ Role } \\
\hline Corporate & 16.7 & \\
\hline Others & 83.3 & \\
\hline Size (i.e., number of members of each subunit) & & $7.8(4.8)$ \\
\hline
\end{tabular}

others. Activity spread accounts for the tendency of managers to be particularly active- namely, to communicate with many others, contributing to information spreading.

Closure configurations test the propensity of managers to form subgroups (Snijders et al., 2006) and are generally associated to redundant information. Transitive closure implies that managers are more likely to communicate with colleagues if they share multiple communication partners. Cyclic closure tests whether information sharing occurs within subgroups without any expectation of being reciprocated. Finally, 2-paths tests the likelihood that the same managers are sought and seek colleagues as communication partners. Since these individuals would connect those from whom they receive information to those to whom they give information, 2-paths could be interpreted as tendency against forming subgroups.

Structural higher-level configurations (Table 5) are the focus of multilevel modeling exercises. Affiliation based closure - $2 \mathrm{a}$ in the previous list - tests whether managers are more likely to talk to colleagues affiliated to the same subsidiary — namely, propensity against boundary spanning.

Cross-level assortativity statistics - class 3a-test the tendency of managers active/popular in the communication network to be affiliated to active/popular subsidiaries in the hierarchical network. Cross-level in-degree assortativity tests whether managers sought as communication partners by many colleagues are likely to be affiliated to subsidiaries receiving many ties in the formal 
Table 4. Exponential Random Graph Models (ERGMs) Lower-Level Structural Configurations.

Configuration
Density
Reciprocity
Activity spread
colleagues
2endency of organizational members to communicate with
reciprocating colleagues

Note: Circles denote individuals, and black links denote (informal) communication relations between pairs of individuals.

organizational network-namely, hierarchically subordinate subsidiaries. Cross-level out-degree assortativity accounts for the opposite effect - namely, the likelihood that managers sharing information with many colleagues are affiliated to subsidiaries, to which many others have to report (i.e., hierarchically superordinate).

Cross-level alignment configurations - class 3a-account for the propensity of members of different subsidiaries to talk to each other if their subsidiaries are connected. Hence, these configurations capture the likelihood that informal ties spanning boundaries defined around subsidiaries are sustained by formal organizational ties. Cross-level alignment entrainment implies that interpersonal ties follow the hierarchical ordering imposed by the formal structure, thus controlling for a tight coupling between formal and informal relations (McEvily et al., 2014). Managers are likely to talk to colleagues affiliated to subsidiaries that are hierarchically dependent on their own subsidiary. The exchange version controls for a loose coupling and can be interpreted as managers' propensity toward inverting the hierarchy, building communication ties with colleagues affiliated to hierarchically superordinate subsidiaries. The exchange reciprocal B configuration accounts for managers' likelihood to reduce the hierarchical distance building reciprocal ties with colleagues affiliated to subsidiaries with which a hierarchical link exists.

Finally, we specify a set of covariate configurations (see Table 6). For interpersonal communication, we include the Covariate match statistic — class 1b. It tests whether managers are more likely 
Table 5. Multilevel Exponential Random Graph Models (MERGMs) Higher-Level Structural Configurations.

\begin{tabular}{|c|c|c|}
\hline Configuration & Representation & Qualitative Interpretation \\
\hline Affiliation based closure & & $\begin{array}{l}\text { Tendency of organizational members to communicate with } \\
\text { colleagues based on common membership in subunits }\end{array}$ \\
\hline $\begin{array}{l}\text { Cross-level in-degree } \\
\text { assortativity }\end{array}$ & & $\begin{array}{l}\text { Tendency of popular organizational members in communicati } \\
\text { network to be affiliated to popular (i.e., hierarchically } \\
\text { subordinate) subunits in interunit network }\end{array}$ \\
\hline $\begin{array}{l}\text { Cross-level out-degree } \\
\text { assortativity }\end{array}$ & & $\begin{array}{l}\text { Tendency of active organizational members in communicatio } \\
\text { network to be affiliated to active (i.e., hierarchically } \\
\text { superordinate) subunits in interunit network }\end{array}$ \\
\hline $\begin{array}{l}\text { Cross-level alignment } \\
\text { entrainment }\end{array}$ & & $\begin{array}{l}\text { Tendency of organizational members to communicate with } \\
\text { colleagues affiliated to subunits hierarchically subordinate t } \\
\text { their subunit }\end{array}$ \\
\hline $\begin{array}{l}\text { Cross-level alignment } \\
\text { exchange }\end{array}$ & & $\begin{array}{l}\text { Tendency of organizational members to communicate with } \\
\text { colleagues affiliated to subunits hierarchically superordinate } \\
\text { their subunit }\end{array}$ \\
\hline $\begin{array}{l}\text { Cross-level alignment } \\
\text { exchange reciprocal B }\end{array}$ & & $\begin{array}{l}\text { Tendency of organizational members to communicate with } \\
\text { reciprocating colleagues affiliated to subunits with which a } \\
\text { hierarchical relation exists }\end{array}$ \\
\hline
\end{tabular}

Note: Circles denote individuals and squares denote organizational subunits (subsidiaries in our case). Solid black links denote (informal) communication relations between pairs of individuals, while dashed black links denote (hierarchical) subordination relations ties between pairs of subunits. Grey links (between circles and squares) denote affiliation ties of individuals to subunits (containment relations).

to communicate with colleagues similar to them with respect to various personal (gender, nationality) and work-related (function, company grade, and tenure) attributes.

The covariate matching process is also investigated for multilevel interdependences - class $3 b$. Cross-level alignment individual covariate match enters the model as entrainment, exchange, and exchange reciprocal $B$ configurations for individual grade and membership in organizational function. These configurations verify whether various types of association between lower- and higherlevel ties are more likely when managers are similar with respect to the specified attribute.

Finally, we specify cross-level alignment entrainment and cross-level alignment exchange subunit covariate match also for subsidiaries' country, role, and size.

\section{Model Estimation and Evaluation}

To account for the interdependence between ties, the estimation of MERGM parameters relies on Monte Carlo Markov Chain Maximum Likelihood (MCMCML) - a simulation-based technique (Hunter \& Handcock, 2006; Snijders, 2002). 
Table 6. Exponential Random Graph Models (ERGMs) and Multilevel Exponential Random Graph Models (MERGMs) Lower- and Higher-Level Covariate Configurations.

Configuration
Covariate match
Cross-level alignment entrainment
individual covariate match
Cross-level alignment exchange
individual covariate match
reciprocal B individual covariate
match
Cross-level alignment entrainment
subunit covariate match

Note: Black denotes an individual or a subunit with a relevant attribute.

The key idea of MCMCML is to simulate a distribution of random graphs from a set of starting parameter values, which are estimated from the data, and to refine the estimated parameter values by comparing this distribution with the observed graph. The Monte Carlo simulation procedure establishes a Markov chain of graphs that, under suitable conditions, will converge to the stationary desired exponential random graph distribution. Various algorithms can be used to produce such a Markov chain. The most popular are the Gibbs sampling and the Metropolis-Hastings algorithm (Snijders, 2002).

In detail, the observed network $\boldsymbol{m}$ is assumed as a single observation of a distribution of random networks $\boldsymbol{M}$ with the same number of actors of $\boldsymbol{m}$, namely, $(v \times u)$. In the case study, for example, the number of lower-level actors $(v)$ is 47 , the number of higher-level actors $(u)$ is 6 , and the set of possible networks is $(u \times[u-1] \times u \times v \times v \times[v-1])=18,290,520$. Each network is assigned a probability of occurrence, depending on the model predictors and related parameters. Hence, the range of possible networks and their probability of realization under the model are represented by a probability distribution. The networks that most resemble the observed network have a higher probability of occurrence. The iterative estimation process, uses the observed network as a guide and consists in selecting parameter values that reproduce the observed network well, applying a maximum likelihood estimation criterion. To progressively approximate the likelihood and refine the parameter estimates, a number of networks are sampled from the 
space of possible networks of size $(v \times u)$, using the probability distribution (with the initial parameter estimates) and compared to the observed network.

The process is repeated until the estimates stabilize (Robins et al., 2007). To evaluate stabilization of the estimates, after each estimation run, a sample of networks is simulated using the model estimates and compared to the observed networks. This is done by computing a $t$ ratio for each estimated statistic. This $t$ ratio consists in the difference between the observed statistic and the mean statistic from the simulated networks, divided by the standard deviation. An absolute $t$ ratio value smaller than 0.1 indicates that the corresponding statistic is well captured by the empirical model and that the parameter estimate converges to the true value. All $t$ ratio values of the included statistics smaller than 0.1 suggest that the model converges and is capable of reproducing the selected effects.

A similar procedure is used also to evaluate the overall goodness of fit of the convergent modeland to compare alternative model specifications. The distribution of graphs implied by the model is simulated using the parameter estimates as initial values. Then a number of network features is selected, and the goodness of fit is assessed by comparing the observed values to the estimated distribution of that feature implied by the model itself (Goodreau, 2007; Hunter, Goodreau, \& Handcock, 2008). The first type of features are MERGM configurations not included in the model, which are tested in order to verify whether the set of included statistics suffices to explain which tendencies shape the network. The second type involves structural properties of the observed graph, which are tested to verify whether the estimated configurations are capable of reproducing the overall observed network structure. Structural properties include various aspects of the degree distributions - namely, distributions of the number of ties sent and received by each actor - and the clustering coefficients - namely, coefficients for the density of groups of three connected actors in the network (Wasserman \& Faust, 1994).

Finally, the model fit is assessed using the $t$ ratios. Since ERGMs are relatively new and complex models, specific statistical tests have still to be developed. The fit assessment is based on a rule of thumb (Hunter et al., 2008; Robins \& Lusher, 2013): an absolute value of the $t$ ratio close to zero, or at least smaller than 2, indicates that the model reproduces the corresponding statistic well. This rule is adopted when comparing alternative model specifications or nested models. The same network features are selected and tested for the estimated models and the corresponding $t$ ratios are computed. Then the model that is capable of reproducing the most network features while ensuring the smallest $t$ ratio values is considered to fit the observed network best.

Estimates and goodness-of-fit diagnostics are produced using the software MPNet (Wang, Robins, Pattison, \& Lazega, 2013), a freely available software specifically designed for MERGMs (see the appendix for details).

\section{Analysis}

\section{Results}

Table 7 reports estimates and associated standard errors of the model parameters. They all refer to convergent models. Similarly to a logistic regression model, the estimates may be interpreted as logodds for the presence of a network tie between two actors versus its absence.

We specify three models ordered in terms of increasing complexity. Model 1 is a baseline or tie independent model, similar to logistic regression. This model includes the intercept (i.e., Density) and the covariate configurations for the interpersonal network, assuming that the likelihood of observing ties is explained by individual characteristics only. Model 2 is the single-level network model. It includes structural and covariate configurations for the interpersonal network. Model 2 allows us to introduce the general ERGM framework and to comment on conclusions that could be drawn from analyzing informal interpersonal communication only, ignoring the hierarchical relations between 
Table 7. Exponential Random Graph Models (ERGMs) and Multilevel Exponential Random Graph Models (MERGMs) Estimates of Interpersonal and Interunit Networks.

\begin{tabular}{|c|c|c|c|}
\hline & $\begin{array}{c}\text { Model I } \\
\text { Tie independent } \\
\text { Network Model } \\
\text { par. (SE) }\end{array}$ & $\begin{array}{c}\text { Model } 2 \\
\text { Lower-Level } \\
\text { Network Model } \\
\text { par. (SE) }\end{array}$ & $\begin{array}{c}\text { Model } 3 \\
\text { Multilevel } \\
\text { Network Model } \\
\text { par. (SE) }\end{array}$ \\
\hline \multicolumn{4}{|l|}{ Lower-level effects } \\
\hline Density & $-2.31(0.21)^{*}$ & $-3.4 \mathrm{I}(0.44)^{*}$ & $-7.52(1.19)^{*}$ \\
\hline Reciprocity & & $3.13(0.46)^{*}$ & $2.62(0.5 \mathrm{I})^{*}$ \\
\hline 2-paths & & $-0.28(0.07)^{*}$ & $-0.19(0.07)^{*}$ \\
\hline Popularity spread $(\lambda=4)$ & & $-0.11(0.18)$ & $-0.08(0.23)$ \\
\hline Activity spread $(\lambda=4)$ & & $0.35(0.15)^{*}$ & $0.50(0.17)^{*}$ \\
\hline Transitive closure $(\lambda=2)$ & & $1.28(0.20)^{*}$ & $0.79(0.2 \mathrm{I})^{*}$ \\
\hline Cyclic closure $(\lambda=2)$ & & $-0.02(0.19)$ & $-0.16(0.20)$ \\
\hline Function match & $0.24(0.21)$ & $0.14(0.14)$ & $0.38(0.22)$ \\
\hline Gender match & $-0.77(0.76)$ & $-0.5 \mathrm{I}(0.57)$ & $0.05(0.8 \mathrm{I})$ \\
\hline Grade match & $0.53(0.16)^{*}$ & $0.23(0.09)^{*}$ & $0.03(0.22)$ \\
\hline Nationality match & $0.12(0.20)$ & $-0.06(0.14)$ & $0.58(0.34)$ \\
\hline Tenure match & $-0.03(0.01)^{*}$ & $-0.02(0.01)^{*}$ & $0.13(0.17)$ \\
\hline \multicolumn{4}{|l|}{ Higher-level effects } \\
\hline Affiliation based closure & & & $2.74(0.67)^{*}$ \\
\hline Cross-level in-degree assortativity & & & $1.17(0.48)^{*}$ \\
\hline Cross-level out-degree assortativity & & & $0.21(0.17)$ \\
\hline Cross-level alignment entrainment & & & $0.50(2.93)$ \\
\hline Cross-level alignment exchange & & & $2.76(3.61)$ \\
\hline Cross-level alignment exchange reciprocal B & & & $2.14(0.93)^{*}$ \\
\hline Alignment entrainment subunit country match & & & $-0.33(0.92)$ \\
\hline Alignment exchange subunit country match & & & $-1.58(1.33)$ \\
\hline Alignment entrainment subunit role match & & & $-0.44(2.88)$ \\
\hline Alignment exchange subunit role match & & & $-3.46(3.67)$ \\
\hline Alignment entrainment subunit size match & & & $-0.09(0.23)$ \\
\hline Alignment exchange subunit size match & & & $-0.20(0.28)$ \\
\hline Alignment entrainment organizational member & nction match & & $2.12(0.95)^{*}$ \\
\hline Alignment exchange organizational member fun & ion match & & $1.90(1.31)$ \\
\hline \multicolumn{3}{|c|}{ Alignment exchange reciprocal B organizational member function match } & $-4.31(1.97)^{*}$ \\
\hline \multicolumn{3}{|c|}{ Alignment entrainment organizational member grade match } & $-1.06(1.13)$ \\
\hline \multicolumn{3}{|c|}{ Alignment exchange organizational member grade match } & $1.46(1.45)$ \\
\hline \multicolumn{3}{|c|}{ Alignment exchange reciprocal B organizational member grade match } & $0.01(2.18)$ \\
\hline
\end{tabular}

*Indicates the ratio of statistic to standard error is greater than 2 (two-sided tests). Standard errors in parentheses.

the subsidiaries. Model 3 is the multilevel network model. It includes multilevel configurations and examines the interdependence between formal intersubsidiary ties and informal interaction. Since Model 3 is our full model, we comment on this, highlighting the differences with Model 1 and 2.

Accounting for higher-level configurations (Model 3) modifies the values of many lower-level parameters and increases the values of the corresponding standard errors. Like in standard regression, multilevel modeling allows better assessing the predictors' variation (Bryk \& Raudenbush, 1992).

As it is typically the case in empirical network data, the Density parameter is negative to indicate that communication ties are costly to establish. This tendency is much stronger in Model 3 than in Models 2 and 1 (respectively, $-7.52,-3.41$, and -2.31). The odds of one organizational member communicating with another versus not communicating decrease from $\left(\mathrm{e}^{-2.31}\right)=0.10$ in Model 1 to $\left(\mathrm{e}^{-3.41}\right)=0.03$ in Model 2 and $\left(\mathrm{e}^{-7.52}\right)=0.001$ in Model 3. The corresponding binary 
probabilities are $\left(\mathrm{e}^{-2.31} /\left[1+\mathrm{e}^{-2.31}\right]\right)=9.03 \%$ in Model $1,\left(\mathrm{e}^{-3.41} /\left[1+\mathrm{e}^{-3.41}\right]\right)=3.20 \%$ in Model 2, and only $\left(\mathrm{e}^{-7.52} /\left[1+\mathrm{e}^{-7.52}\right]\right)=0.05 \%$ in Model 3. This indicates that once we account for the formal structure (Model 3), there is almost no chance of observing "random" communication tiesnamely, ties that are not part of more complex network substructures.

The significantly positive value of the Reciprocity parameter (3.13 in Model 2 and 2.62 in Model 3 ) indicates that managers are likely to build mutual ties and to share information on a not hierarchical basis. This propensity, however, slightly decreases in magnitude from Model 2 to Model 3. In detail, the odds that managers reciprocate a communication relation against not reciprocating it is equal to $\left(\mathrm{e}^{3.13}\right)=22.87$ in Model 2 and $\left(\mathrm{e}^{2.62}\right)=13.74$ in Model 3. The corresponding binary probabilities are $\left(\mathrm{e}^{3.13} /\left[1+\mathrm{e}^{3.13}\right]\right)=95.81 \%$ in Model 2 and $\left(\mathrm{e}^{2.62} /\left[1+\mathrm{e}^{2.62}\right]\right)=93.21 \%$ in Model 3, suggesting a very strong propensity toward reciprocating communication relations. The positive effect of Activity spread ( 0.50$)$ suggests the presence of a restricted number of managers particularly active in communicating with many colleagues. ${ }^{5}$ These managers rely on many others as sources of information and are likely to diversify their range of available knowledge. The combination of a positive Transitive closure - decreasing from Model 2 to Model 3 (1.28 and 0.79, respectively) - and a negative, although not significant, Cyclic closure parameter $(-0.16)$, indicates that managers tend to interact in small subgroups. Akin to a bonding social capital perspective, available information is likely to be redundant and its spread controlled by few members of the subgroups. The significantly negative 2-paths $(-0.19)$ enforces this result, outlining that managers are unlikely to spread information across different groups. Since 2-paths indicates also that the same individuals receive and share information, the negative parameter suggests the existence of a division of roles.

The parameters of several higher-level configurations are significant, indicating an association between information sharing among managers and the hierarchical structure, and suggesting possible mechanisms responsible for such association.

The significantly positive Affiliation based closure parameter (2.74) indicates that managers are likely to communicate with colleagues in the same subsidiary. This result captures the well-known tendency of organizational subunit boundaries to restrict the range of relations and information available for managers (Reagans \& McEvily, 2003). The significantly positive Cross-level indegree assortativity parameter (1.17) suggests that managers more sought after by colleagues as communication partners are affiliated to subsidiaries that have to report to several others - namely, hierarchically subordinate. Hence, information is likely to flow from members of subordinate to members of superordinate subunits. The positive Cross-level alignment exchange reciprocal B (2.14) outlines that managers are likely to build mutual relations to others with different affiliation and hierarchical level. The managers span their subsidiary boundaries in sharing information when the interpersonal ties are sustained by hierarchical dependence ties between the subsidiaries. The formal interunit relation provides managers with opportunity to meet and share information (Kleinbaum et al., 2013). Combined with the statistically nonsignificant Cross-level alignment entrainment and exchange parameters, the Cross-level alignment exchange reciprocal $B$ emphasizes the importance of mutual relations as a key driver of boundary spanning.

The significance of the individual covariates changes across model specifications. The Grade and Tenure match configurations are significant in the first two models but disappear in Model 3. When we ignore the higher-level network, we find that managers are likely to interact with colleagues similar in terms of status (as measured by job grade) and experience (as measured by tenure).

When the organizational hierarchical structure is accounted for (Model 3), these individual characteristics no longer have a significant effect on the presence of communication ties between individuals. In Model 3, the propensity toward interacting with similar colleagues seems to operate only through organizational structure. Contrary to the tendency illustrated previously, the positive Cross-level alignment entrainment function match (2.12) suggests that managers in the same functional area tend to talk to colleagues affiliated to subsidiaries that hierarchically depend on their 
own subsidiary. Membership in the same professional function encourages the establishment of boundary spanning ties that preserve the hierarchical ordering. This effect of intersubsidiary hierarchy within the same functional area is confirmed by the negative Cross-level alignment exchange reciprocal B function match parameter (-4.31).

\section{Model Evaluation}

We conclude our analysis by testing the ability of the estimated models to reproduce salient characteristics of the observed network as a whole. We find that this ability is significantly higher for the multilevel network model.

We follow recommended best practices in the analysis of ERGMs (Hunter et al., 2008) and produce a sample of 1,000 graphs drawn from the random graph distribution simulated based on the empirical estimates. We extract these graphs from a simulated distribution of graphs after $1,000,000$ iterations and after a 100,000-iteration burn-in phase. ${ }^{6}$ Since both networks $\boldsymbol{X}$ and $\boldsymbol{A}$ are considered exogenous in the estimation process, the goodness-of-fit check focuses on the interpersonal network and on its network features.

As we discussed, any feature of interest in the observed graph can be compared to the distribution of such features in the model. To make the three models comparable (see Table 7), we select the same network features for testing. In detail, being our models nested, we pick up the features of interest for the complete model (Model 3) and check how many of them are well fitted also by simpler models (Model 1 and Model 2). We use the $t$ ratio to detect the location of the observed feature in this distribution. Absolute values larger than 2 suggest that the observed graph differs from the distribution implied by the model in the corresponding feature (Hunter et al., 2008). Hence, the model is not capable of capturing the feature. Indeed, the closer to zero the $t$ ratio values, the better the fit. Table 8 reports comparisons for a variety of crucial characteristics of the interpersonal network $\boldsymbol{B}$ : features of the distributions of incoming and outgoing ties - namely, indegree and outdegree distributions - as well as a set of coefficients controlling for the existence of subgroups of three connected actors - generalized clustering coefficients (GCC; Luce \& Perry, 1949). According to the direction of ties, the generalized clustering coefficient may take different forms. Following the empirical model specification, we control for the transitive (i.e., transitive closure) and cyclic (i.e., cyclic closure) forms. The $t$ ratio values show that the multilevel network model (Model 3) captures much better than the others these features of the observed networks.

In detail, for Model 1, three of the six $t$ ratio values reported in Table 8 are significantly larger than the threshold 2 in absolute magnitude. Consequently, it is not possible to reproduce the network features well without accounting for the local interdependence structures implied by ERGMs. Hence, this result points to the usefulness of the ERGM framework. For Models 2 and 3, all the $t$ ratio values are significantly smaller than the threshold. Indeed, Model 3 provides much more accurate estimates of all the network characteristics, as most $t$ ratio values become closer to zero.

We investigate goodness of fit also on the set of MERGM configurations not parameterized in the estimated models. Since we do not have any a priori assumptions on which configurations the empirical models should be capable of capturing, we test all the structural and covariate statistics that can be included to modeling the interpersonal network as well as the interaction across levels. For brevity, we do not report the observed and simulated mean of each statistic as well as the related $t$ ratio value, but we just comment on the results. Also in this case, we find that Model 3 ensures a significant improvement in the fit for the most statistics: it reproduces 97 out of the 99 statistics that can be specified (i.e., the corresponding absolute $t$ ratio values are smaller than 2). Models 1 and 2 have a considerably poorer fit: they reproduce only 44 and 64 statistics, respectively. 
Table 8. Goodness-of-Fit Diagnostics for Selected Structural Network Properties.

\begin{tabular}{|c|c|c|c|c|c|c|c|}
\hline \multirow[t]{3}{*}{ Statistics } & \multirow[b]{3}{*}{ Observed } & \multicolumn{2}{|c|}{ Model I } & \multicolumn{2}{|c|}{ Model 2} & \multicolumn{2}{|c|}{ Model 3} \\
\hline & & Simulated & & Simulated & & Simulated & \\
\hline & & $\begin{array}{l}\text { Mean } \\
(S E)\end{array}$ & $\begin{array}{c}t \\
\text { ratio }\end{array}$ & $\begin{array}{l}\text { Mean } \\
(S E)\end{array}$ & $\begin{array}{c}t \\
\text { ratio }\end{array}$ & $\begin{array}{l}\text { Mean } \\
(S E)\end{array}$ & $\begin{array}{c}t \\
\text { ratio }\end{array}$ \\
\hline $\begin{array}{l}\text { Standard deviation in-degree } \\
\text { distribution }\end{array}$ & 1.85 & $1.92(0.21)$ & -0.34 & $1.84(0.19)$ & 0.05 & $1.85(0.18)$ & -0.00 \\
\hline Skewness in-degree distribution & -0.20 & $0.45(0.33)$ & -1.95 & $-0.01(0.29)$ & -0.66 & $0.01(0.26)$ & -0.77 \\
\hline $\begin{array}{l}\text { Standard deviation out-degree } \\
\text { distribution }\end{array}$ & 2.65 & $1.92(0.21)$ & 3.46 & $2.50(0.25)$ & 0.61 & $2.55(0.27)$ & 0.38 \\
\hline Skewness out-degree distribution & 0.69 & $0.42(0.31)$ & 0.86 & $0.25(0.29)$ & 1.52 & $0.44(0.33)$ & 0.74 \\
\hline GCC Transitive closure & 0.49 & $0.08(0.01)$ & 29.27 & $0.46(0.05)$ & 0.81 & $0.50(0.05)$ & -0.14 \\
\hline GCC Cyclic closure & 0.42 & $0.08(0.02)$ & 16.91 & $0.40(0.05)$ & 0.37 & $0.44(0.05)$ & -0.33 \\
\hline
\end{tabular}

Note: Standard errors in parentheses.

\section{Conclusions}

In this article, we have presented newly derived multilevel exponential random graph models for the analysis of multilevel networks in organizations (Wang, Robins, Pattison, \& Lazega, 2013). More specifically, we have: (1) framed MERGMs as one feasible analytical strategy to represent multilevel mechanisms of network tie formation, (2) illustrated the distinctive analytical insights that these models provide on the multilevel dependencies inherent in social networks within organizations, and (3) discussed how such insights may contribute to a more detailed understanding of the relations between formal structure and informal networks in organizations.

We have emphasized the specification and estimation of parameters corresponding to local configurations of network ties across levels. MERGMs are the only models that afford direct estimation of such parameters. This emphasis clearly marks the fundamental difference between the class of multilevel models for social networks (Li, 2013) and the class of multilevel social network models that MERGMs represent. Multilevel models for networks can control for network dependencies in observations across levels, but they offer only limited assistance in developing and testing hypothesis about the specific forms that multilevel interdependences might take in any specific data set. The main analytical objective of multilevel network models is to represent these interdependencies directly and explicitly. Detecting specific forms assumed by the interdependence of the relational behavior of lower-level actors on the relational behavior of the higher-level actors in which lower-level actors are members, MERGMs allow assessing lower-level actors' autonomy and real contribution to their position in the interpersonal network structure.

We have illustrated the empirical value of MERGMs examining information sharing relations among members of the top management team within a multiunit organization. Using data we have collected on relations of hierarchical subordination and informal communication between the managers, we have shown how MERGMs may be specified to address a number of core concerns in multilevel organizational analysis. We focused our discussion on the tendency of informal information sharing relations to cross-cut the formal subunit boundaries. We have documented specific ways in which boundary crossing ties are sustained by hierarchical organizational structure (Reagans \& McEvily, 2003).

We have shown, further, that multilevel network models take us beyond the empirical regularities documented in received organization research. We have indicated various ways in which ties between subsidiaries can affect interpersonal sharing of information. In doing so, we have suggested that well-known properties of informal social networks (i.e., actor centrality, reciprocity of ties) may 
actually depend on the properties of the settings in which interaction occurs - and not just on the characteristics of the individuals involved in interaction (Lomi \& Stadtfeld, 2014). We reported results showing that the most popular managers in the communication network are member in the most popular subsidiaries. This seems to be particularly salient in our study because it suggests that "centrality" - one of the most common network measures used in empirical studies of organizational behavior (Brass \& Burkhardt, 1992), leadership (Balkundi \& Kilduff, 2006), and human resources management (Sparrowe, Liden, Wayne, \& Kraimer, 2001) — comes also from membership in central subsidiaries rather than individual attributes or even network positions. If replicated, this result might lead to a systematic reevaluation of the meaning and causal standing of centrality and other popular network constructs that are extensively used in organizational research.

We have shown, finally, that boundary-spanning ties tend to be supported by and co-occur with formal relations between the subsidiaries. Managers in different subsidiaries are unlikely to entertain informal relations with one another unless the subsidiaries are themselves connected. When supported by formal ties, informal ties between managers are characterized by significant tendencies toward reciprocity. This is, therefore, the key mechanism that allows informal interaction to span formal boundaries.

In closing, it seems appropriate to acknowledge the main limitations of the modeling approach that we have proposed. These limitations suggest caution in the interpretation of the results we have reported but also indicate clear directions for future research. First, MERGMs are not generalpurpose regression-like models. They are a specialized class of models developed for assessing interdependences between binary tie variables. They are valuable only to the extent that the issue being addressed requires explicit modeling of the mechanisms generating interdependences between network ties. The relatively limited range of data structures that may be used to estimate MERGMs is compensated, in part, by the unique possibility afforded by MERGMs to model explicitly endogenous tie interdependence mechanisms that in more established hierarchical linear models can only be corrected for generically. To broaden the appeal and applicability of MERGMs, future research will have to extend the basic setup that we have described in this article to more general and flexile data structures.

Second, MERGMs share most of the limitations of the ERGM class of models from which they derive. The main of such limitations is probably that MERGMs are models for cross-sectional data. This limits our understanding of the specific mechanisms underlying the formation and change of network structures in organizations. At best, estimated values of MERGM parameters represent cross-sectional traces of causal mechanisms underlying the interdependence structures observed in the data. The cross-sectional nature of MERGMs also limits our ability to tease out the separate effects on the formation of network ties of individual (exogenous) characteristics of the actors (people in our case) and of the endogenously determined positions they occupy in the network of social and communication relations. Stochastic actor-oriented models for dynamic multilevel networks are probably more useful to address such questions (Snijders, Lomi, \& Torlò, 2013). Research extending ERGMs to longitudinal data is promising, but it is only moving its first steps (Koskinen \& Lomi, 2013). Another limitation concerns the scant assistance offered by standard statistical testing procedures, especially in respect to model selection and goodness-of-fit assessment. As we have emphasized, the peculiar characteristics of the MERGM framework - the interdependence between observations (i.e., ties) and, therefore, between statistics and related parameters - implies that standard statistical testing cannot be applied directly to MERGM class of models and is poorly informative. We have illustrated, nonetheless, that the rules of thumb - on which fit assessment currently relies - allow successfully comparing alternative model specifications (and nested models) and selecting the model that best reproduces the empirical network. Similar considerations apply to the comparison among parameters, which is a well-known issue in ERGM studies - at the heart of current research on this class of models. Testing the difference between parameters within and across models is currently not possible. Parameter strength may be interpreted only in the context of an empirical specification, and 
the contribution of each parameter has to be interpreted with everything else assumed equal. Bayesian exponential random graph models (BERGMs) are being developed to provide a probabilistic framework for comparing models and model parameters (Caimo \& Lomi, 2015).

In spite of these limitations, we think that the results we have presented clearly demonstrate the benefits of accounting for potential multilevel mechanisms when modeling social networks. For researchers interested in social networks in organizations, the models for multilevel networks that we have discussed and illustrated provide a useful addition to the set of more general multilevel models currently adopted in organizational research.

\section{Appendix}

Multilevel exponential random graph models are estimated using MPNet (http://sna.unimelb.edu.au/ PNet), a free software with a user-friendly interface.

\section{Creating Input Files (Data)}

In order to perform the analysis with MPNet, the input data have to be prepared and saved in the correct format. A general specification consists of the three network files and a few attribute files at least. All the files are in text format.

Network data. A separate text file has to be created for each network. The file consists in a square binary matrix for network $\boldsymbol{A}$ and $\boldsymbol{B}$, and a rectangular binary matrix for network $\boldsymbol{X}$. For instance, the matrices used in our empirical exercise are as follows:

$\boldsymbol{A}$ is a square matrix of size $(6 \times 6)$. Its generic entry $a_{l k}$ takes value 1 if the row element (subsidiary) $l$ is hierarchically superordinate to the column element (subsidiary) $k$ and 0 otherwise. The diagonal values are set at 0 by default.

$\boldsymbol{B}$ is a square matrix of size $(47 \times 47)$. Its generic entry $b_{i j}$ takes value 1 if the row element (manager) $i$ communicates with the column element (manager) $j$ and 0 otherwise. The diagonal values are set at 0 by default.

$\boldsymbol{X}$ is a rectangular matrix of size $(47 \times 6)$. Its generic entry $x_{i l}$ takes value 1 if the row element (manager) $i$ is affiliated to the column element (subsidiary) $l$ and 0 otherwise.

Actor data. A separate attribute text file has to be created for each set of actors and each type of attributes (binary, categorical, continuous).

Each set contains as many rows as the number of elements (subsidiary, manager) and as many columns as the number of attributes.

\section{Running the Analysis}

Specifying and estimating MERGMs requires performing a set of steps. Once the data files have been uploaded into MPNet, the effects that are expected to affect the multilevel network structure have to be selected. Usually, models are estimated in order of increasing complexity. It is advisable to start with a very simple model and make it more complex adding few effects in each run. First, a lower-level model is specified, estimated, and tested. Then, multilevel effects are added. After each run and before more complex models can be fitted, the model convergence has to be checked. In detail:

1. Import the input text files in MPNet.

2. Select which lower-level effects to include in the model specification. The selection is driven by theoretical hypotheses about the relational behaviors which are expected to characterize the relation investigated. 
3. Specify the MCMCML parameter values (i.e., number of subphases for iterations in the estimation process, maximum estimation runs, sample size of networks simulated at step 5) and start an estimation run. The MCMC algorithm is set internally and cannot be changed.

4. Check the covariance of effects in the output file. Like in standard regression models, a particularly high covariance between pairs of effects may indicate that they capture the same relational behavior and may inflate the $p$ value of even important effects. It is advisable to consider whether to delete some of them.

5. Check the model convergence in the output file. A model is considered fully convergent if the absolute values of the $t$ ratios for all the included effects are smaller than 0.1 . This step is performed internally in MPNet. The number of iterations is set at 500 by default. To gain convergence, it is possible to fine-tune the MCMCML parameter values (i.e., number of subphases in the estimation process, maximum estimation runs, etc. can be increased) and repeat the estimation.

6. Once a fully convergent model is obtained, update the estimates.

7. Check the goodness of fit of the model, according to the procedure illustrated in the article. Like in standard MCMCML estimation procedure, the sample size of the simulated networks to extract as well as the overall number of iterations and the number of iterations in the "burn-in" period have to be specified. Following best practices in ERGM estimation, these MCMCML parameter values are usually set to the default values mentioned in the article. The results of the goodness-of-fit check are reported in the goodness-of-fit file.

8. Include further sets of effects and repeat Steps 3 through 7 until a successful model is obtained.

More details on the list of effects that can be specified as well as on the estimation and testing procedures are reported in the PNet and MPNet manuals (http://sna.unimelb.edu.au/PNet).

\section{Additional Points}

If one is interested in assessing the effect of shared - possibly multiple - affiliations to nonconnected subunits on lower-level interaction within and between subunits, the higher-level network need not be included. Cross-level configurations are not tested.

\section{Declaration of Conflicting Interests}

The author(s) declared no potential conflicts of interest with respect to the research, authorship, and/or publication of this article.

\section{Funding}

The author(s) disclosed receipt of the following financial support for the research, authorship, and/or publication of this article: The research leading to this article was made possible, in part, by financial support provided by the Schweizerscher Nationalfonds (Swiss National Science Foundation, Project Number CRSII1_147666).

\section{Notes}

1. In non-experimental studies based on sampling, ignoring nonindependence could result in: (1) too small an estimate of standard errors associated with model parameters and, as a consequence, the detection of an effect which is not significant (Type I error); (2) too little power of statistical tests and, as a consequence, a failure to detect an effect which is significant (Type II error).

2. For example, the tie $b_{i j}$ can be included in either a reciprocal dyad with the tie $b_{j i}$, or a triangle with the ties $b_{j h}$ and $b_{i h}$.

3. Five consultants were also included in the list because of the direct and personal relations with the presidentfounder of the group and because of their crucial role in boat design. In the text we will refer to the 47 
respondents generically as managers unless the distinction between managers and consultants is essential to the argument.

4. Our "bottom-up" approach to reconstructing the intraorganizational hierarchy between the subsidiary units has a high degree of nominal validity because all the relations of subordination flow from the corporate center (which is superordinate) to the subsidiaries. Our approach also allows us, however, to discover hierarchical relations between subsidiaries. See Figure 1 .

5. The parameter $\lambda$ takes value 4 , which corresponds to a highly skewed out-degree distribution. Thus, a small number of very active organizational members coexist with a majority of others who are likely to interact with few colleagues (Hunter, 2007; Hunter \& Handcock, 2006).

6. The burn-in refers to the practice of disregarding (and throwing away) the initial portion of $t$ steps or iterations of a Markov chain sample, so that the effect of the initial values on the estimation process is minimized. This portion of $t$ steps is indicated as burn-in period. After the burn-in period, the Markov chain is run normally and each iteration is used in the MCMC calculations. The burn-in period is common to many MCMC algorithms.

\section{References}

Antonakis, J., Bendahan, S., Jacquart, P., \& Lalive, R. (2010). On making causal claims: A review and recommendations. The Leadership Quarterly, 21(6), 1086-1120.

Argote, L., McEvily, B., \& Reagans, R. (2003). Managing knowledge in organizations: An integrative framework and review of emerging themes. Management Science, 49(4), 571-582.

Balkundi, P., \& Kilduff, M. (2006). The ties that lead: A social network approach to leadership. The Leadership Quarterly, 17(4), 419-439.

Baum, J. A., \& Ingram, P. (2002). Interorganizational learning and network organization: Toward a behavioral theory of the interfirm. In The economics of choice, change, and organization: Essays in memory of Richard M. Cyert (pp. 191-218). London: Edward Elgar.

Beal, D. J., \& Dawson, J. F. (2007). On the use of Likert-type scales in multilevel data: Influence on aggregate variables. Organizational Research Methods, 10(4), 657-672.

Bell, S. T., Towler, A. J., \& Fisher, D. M. (2011). A multilevel examination of the influence of trainee-trainer gender dissimilarity and trainee-classroom gender composition dissimilarity on trainee knowledge acquisition. Human Resource Development Quarterly, 22(3), 343-372.

Bliese, P. D., Chan, D., \& Ployhart, R. E. (2007). Multilevel methods: Future directions in measurement, longitudinal analyses, and nonnormal outcomes. Organizational Research Methods, 10, 551-563.

Bliese, P. D., Halverson, R. R., \& Schriesheim, C. A. (2002). Benchmarking multilevel methods in leadership: The articles, the model, and the data set. The Leadership Quarterly, 13(1), 3-14.

Borgatti, S. P., \& Foster, P. C. (2003). The network paradigm in organizational research: A review and typology. Journal of Management, 29(6), 991-1013.

Brass, D. J. (2000). Networks and frog ponds: Trends in multilevel research. In K. J. Klein \& W. J. Kozlowski (Eds.), Multilevel theory, research, and methods in organizations: Foundations, extensions, and new directions (pp. 557-571). San Francisco, CA: Jossey-Bass.

Brass, D. J., \& Burkhardt, M. E. (1992). Centrality and power in organizations. In N. Nohria \& R. Eccles (Eds.), Networks and organizations: Structure, form, and action (pp. 191-215). Boston, MA: Harvard Business School Press.

Brass, D. J., \& Burkhardt, M. E. (1993). Potential power and power use: An investigation of structure and behavior. Academy of Management Journal, 36(3), 441-470.

Brass, D. J., Galaskiewicz, J., Greve, H. R., \& Tsai, W. (2004). Taking stock of networks and organizations: A multilevel perspective. Academy of Management Journal, 47(6), 795-817.

Brass, D. J., Labianca, G., Mehra, A., Halgin, D. S., \& Borgatti, S. P. (Eds.). (2014). Research in the sociology of organizations. Bradford, UK: Emerald Publishing.

Bryk, A. S., \& Raudenbush, S. W. (1992). Hierarchical linear models: Applications and data analysis methods. Newbury Park, CA: Sage. 
Burt, R. S. (1992). The social structure of competition. In N. Nohria \& R. Eccles (Eds.), Networks and organizations: Structure, form, and action (pp. 57-91). Boston, MA: Harvard Business School Press.

Burt, R. S. (2004). Structural holes and good ideas. American Journal of Sociology, 110(2), 349-399.

Caimo, A., \& Lomi, A. (2015). Knowledge sharing in organizations. A Bayesian analysis of the role of reciprocity and formal structure. Journal of Management, 41(2), 665-691.

Carpenter, M. A., Li, M., \& Jiang, H. (2012). Social network research in organizational contexts a systematic review of methodological issues and choices. Journal of Management, 38(4), 1328-1361.

Carson, J. B., Tesluk, P. E., \& Marrone, J. A. (2007). Shared leadership in teams: An investigation of antecedent conditions and performance, Academy of Management Journal, 50(5), 1217-1234.

Chen, G. (2005). Newcomer adaptation in teams: Multilevel antecedents and outcomes. Academy of Management Journal, 48(1), 101-116.

Contractor, N., Wasserman, S., \& Faust, K. (2006). Testing multi-theoretical multilevel hypotheses about organizational networks: An analytic framework and empirical example. Academy of Management Review, 31(3), 681-703.

Dokko, G., Kane, A. A., \& Tortoriello, M. (2014). One of us or one of my friends: How social identity and tie strength shape the creative generativity of boundary-spanning ties. Organization Studies, 35(5), 703-726.

Fernandez, R. M. (1991). Structural bases of leadership in intraorganizational networks. Social Psychology Quarterly, 54(1), 36-53.

Goodreau, S. M. (2007). Advances in exponential random graph ( $\left.\mathrm{p}^{*}\right)$ models applied to a large social network. Social Networks, 29(2), 231-248.

Granovetter, M. (2005). Business groups and social organization. In N. J. Smelser \& R. Swedberg (Eds.), Handbook of economic sociology (2nd ed., pp. 429-450). New York and Princeton: Russell Sage Foundation and Princeton University Press.

Hansen, M. T. (1999). The search-transfer problem: The role of weak ties in sharing knowledge across organization sub-units. Administrative Science Quarterly, 44(1), 82-111.

Hirst, G., Van Knippenberg, D., Chen, C. H., \& Sacramento, C. A. (2011). How does bureaucracy impact individual creativity? A cross-level investigation of team contextual influences on goal-orientation-creativity relationships. Academy of Management Journal, 54(3), 624-641.

Hofmann, D. A. (1997). An overview of the logic and rationale of hierarchical linear models. Journal of Management, 23(6), 723-744.

Hunter, D. R. (2007). Curved exponential family models for social networks. Social Networks, 29(2), 216-230.

Hunter, D. R., Goodreau, S. M., \& Handcock, M. S. (2008). Goodness of fit of social network models. Journal of the American Statistical Association, 103(481), 248-258.

Hunter, D. R., \& Handcock, M. S. (2006). Inference in curved exponential family models for networks. Journal of Computational and Graphical Statistics, 15(3), 565-583.

Ibarra, H., Kilduff, M., \& Tsai, W. (2005). Zooming in and out: Connecting individuals and collectivities at the frontiers of organizational network research. Organization Science, 16(4), 327-331.

Kilduff, M., \& Krackhardt, D. (1994). Bringing the individual back in: A structural analysis of the internal market for reputation in organizations. Academy of Management Journal, 37(1), 87-108.

Klein, K. J., \& Kozlowski, S. W. J. (2000). Multilevel theory, research, and methods in organizations: Foundations, extensions, and new directions. San Francisco, CA: Jossey-Bass.

Kleinbaum, A. M., Stuart, T. E., \& Tushman, M. L. (2013). Discretion within constraint: Homophily and structure in a formal organization. Organization Science, 24(5), 1316-1336.

Koskinen, J., \& Lomi, A. (2013). The local structure of globalization. Journal of Statistical Physics, 151(3-4), 523-548.

Kozlowski, S. W. J., \& Klein, K. J. (2000). A multilevel approach to theory and research in organizations: Contextual, temporal, and emergent processes. In K. J. Klein \& S. W. J. Kozlowski (Eds.), Multilevel theory, research, and methods in organizations: Foundations, extensions, and new directions (pp. 3-90). San Francisco, CA: Jossey-Bass. 
Lazega, E., Jourda, M. T., Mounier, L., \& Stofer, R. (2008). Catching up with big fish in the big pond? Multilevel network analysis through linked design. Social Networks, 30(2), 159-176.

Li, M. (2013). Social network and social capital in leadership and management research: A review of causal methods. The Leadership Quarterly, 24(5), 638-665.

Lomi, A., \& Larsen, E. (2001). Dynamics of organizations. AAAI and MIT Press.

Lomi, A., Lusher, D., Pattison, P. E., \& Robins, G. L. (2013). The focused organization of advice relations: A study in boundary crossing. Organization Science, 25(2), 438-457.

Lomi, A., \& Stadtfeld, C. (2014). Social networks and social settings: Developing a coevolutionary view. In J. Friedrichs \& A. Nonnenmacher (Eds.), Social contexts and social mechanisms. Special issue of the Kölner Zeitschrift für Soziologie und Sozialpsychologie, 66(1): 395-415.

Luce, R. D., \& Perry, A. D. (1949). A method of matrix analysis of group structure. Psychometrika, 14(1), 95-116.

Lusher, D., Koskinen, J., \& Robins, G. L. (2013). Exponential random graph models for social networks: Theory, methods, and applications. Cambridge, UK: Cambridge University Press.

March, J. G., \& Simon, H. A. (1958). Organizations. New York, NY: John Wiley and Sons.

McCulloh, I., Armstrong, H., \& Johnson, A. (2013). Social network analysis with applications. New York, NY: Wiley.

McEvily, B., Soda, G., \& Tortoriello, M. (2014). More formally: Rediscovering the missing link between formal organization and informal social structure. The Academy of Management Annals, 8(1), 299-345.

McLaren, T. S., Head, M. M., Yuan, Y. F., \& Chan, Y. E. (2011). A multilevel model for measuring fit between a firm's competitive strategies and information systems capabilities. MIS Quarterly, 35(4), 909-929.

Mehra, A., Kilduff, M., \& Brass, D. J. (2001). The social networks of high and low self-monitors: Implications for workplace performance. Administrative Science Quarterly, 46(1), 121-146.

Moliterno, T. P., \& Mahony, D. M. (2011). Network theory of organization: A multilevel approach. Journal of Management, 37(2), 443-467.

Monge, P. R., \& Contractor, N. S. (2003). Theories of communication networks. Oxford, UK: Oxford University Press.

Mumford, M. D., Antes, A. L., Caughron, J. J., \& Friedrich, T. L. (2008). Charismatic, ideological, and pragmatic leadership: Multi-level influences on emergence and performance. The Leadership Quarterly, 19(2), 144-160.

Oh, H., Labianca, G., \& Chung, M. H. (2006). A multilevel model of group social capital. Academy of Management Review, 31(3), 569-582.

Pattison, P. E., \& Robins, G. L. (2002). Neighbourhood-based models for social networks. Sociological Methodology, 32, 301-337.

Ployhart, R. E., \& Moliterno, T.P. (2011). Emergence of the human capital resource: A multilevel model. Academy of Management Review, 36(1), 127-150.

Podolny, J. M., \& Baron, J. N. (1997). Resources and relationships: Social networks and mobility in the workplace. American Sociological Review, 62(5), 673-693.

Porter, L., \& Schneider, B. (2014). What was, what is, and what may be in OP/OB. Annual Review of Organizational Psychology and Organizational Behavior, 1(1), 1-21.

Reagans, R., \& McEvily, B. (2003). Network structure and knowledge transfer: The effects of cohesion and range. Administrative Science Quarterly, 48(2), 240-267.

Reagans, R., \& Zuckerman, E. W. (2001). Networks, diversity, and productivity: The social capital of corporate R\&D teams. Organization Science, 12(4), 502-517.

Robins, G. L., Elliott, P., \& Pattison, P. E. (2001). Network models for social selection processes. Social Networks, 23(1), 1-30.

Robins, G. L., \& Lusher, D. (2013). Illustrations: Simulation, estimation and goodness of fit. In D. Lusher, J. Koskinen, \& G. L. Robins (Eds.), Exponential random graph models for social networks: Theory, methods and applications (pp. 167-186). Cambridge, UK: Cambridge University Press. 
Robins, G. L., Snijders, T. A. B., Wang, P., Handcock, M., \& Pattison, P. E. (2007). Recent developments in exponential random graph models for social networks. Social Networks, 29(2), 192-215.

Rousseau, D. M. (1985). Issues of level in organizational research: Multi-level and cross-level perspectives. In L. L. Cummings \& B. M. Staw (Eds.), Research in organizational behavior (pp. 1-37). Greenwich, CT: JAI.

Scherbaum, C. A., \& Ferreter, J. M. (2009). Estimating statistical power and required sample sizes for organizational research using multilevel modeling. Organizational Research Methods, 12(2), 347-367.

Simon, H. A. (1996). The sciences of the artificial. Cambridge, MA: MIT Press.

Snijders, T. A. B. (2002). Markov Chain Monte Carlo estimation of exponential random graph models. Journal of Social Structure, 3(2), 1-40.

Snijders, T. A. B., Lomi, A., \& Torló, V. J. (2013). A model for the multiplex dynamics of two-mode and onemode networks, with an application to employment preference, friendship, and advice. Social Networks, 35(2), 265-276.

Snijders, T. A. B., Pattison, P. E., Robins, G. L., \& Handcock, M. S. (2006). New specifications for exponential random graph models. Sociological Methodology, 36(1), 99-153.

Sparrowe, R. T., Liden, R. C., Wayne, S. J., \& Kraimer, M. L. (2001). Social networks and the performance of individuals and groups. Academy of Management Journal, 44(2), 316-325.

Srivastava, S. B., \& Banaji, M. R. (2011). Culture, cognition, and collaborative networks in organizations. American Sociological Review, 76(2), 207-233.

Tsai, W. (2001). Knowledge transfer in intraorganizational networks: Effects of network position and absorptive capacity on business unit innovation and performance. Academy of Management Journal, 44(5), 996-1004.

Tsai, W. (2002). Social structure of "coopetition" within a multiunit organization: Coordination, competition, and intraorganizational knowledge sharing. Organization Science, 13(2), 179-190.

Tushman, M. (1977). Special boundary roles in the innovation process. Administrative Science Quarterly, 22(4), 587-605.

Wang, P., Robins, G. L., Pattison, P. E., \& Lazega, E. (2013). Exponential random graph models for multilevel networks. Social Networks, 35(1), 96-115.

Wang, P., Robins, G. L., Pattison, P. E., Lazega, E., \& Jourda, M. T. (2015). Social selection models for multilevel networks. Social Networks (forthcoming).

Wasserman, S., \& Faust, K. (1994). Social network analysis: Methods and applications (Vol. 8). Cambridge, UK: Cambridge University Press.

Wright, P. M., \& Boswell, W. R. (2002). Desegregating HRM: A review and synthesis of micro and macro human resource management research. Journal of Management, 28(3), 247-276.

Yammarino, F. J., Dionne, S. D., Uk Chun, J., \& Dansereau, F. (2005). Leadership and levels of analysis: A state-of-the-science review. The Leadership Quarterly, 16(6), 879-919.

Zohar, D., \& Luria, G. (2005). A multilevel model of safety climate: cross-level relationships between organization and group-level climates. Journal of Applied Psychology, 90(4), 616-628.

\section{Author Biographies}

Paola Zappa is a post doctoral fellow in the Faculty of Economics and Social Network Analysis Research (SoNAR) Center at the University of Italian Switzerland, Lugano. Her research currently focuses on multilevel network theories of organizations.

Alessandro Lomi is a professor of organizational theory and behavior in the Faculty of Economics at the University of Italian Switzerland, Lugano where he directs the Social Network Analysis Research (SoNAR) Center. His research interests include organizational theory and the analysis of social networks within and between organizations. 